\title{
Obstruction of the Left Ventricular Outflow Tract After Mitral Valvuloplasty with Implantation of Gregori's Ring
}

\author{
Roberto G. de Carvalho, Gustavo K. Pimentel, Luciano de Oliveira, Márcia M. da Silveira, \\ Alexandre Alessi, Dalton B. Precoma \\ Curitiba, PR - Brazil
}

\begin{abstract}
Mitral valvuloplasty is efficient for repairing mitral valve disease with few complications. In some cases, obstruction of the left ventricular outflow tract may occur due to systolic anterior motion of the mitral valve. We report the case of a patient with this complication and a pressure gradient between the left ventricle and the aorta of $130 \mathrm{~mm} \mathrm{Hg}$ after mitral valvuloplasty with implantation of a Gregori's ring. The management was clinical with suspension of the vasoactive drugs and introduction of a beta-blocker. Two years after the surgery, the patient is asymptomatic and has a normal life.
\end{abstract}

Mitral valvoplasty is a reproducible procedure, in which the degree of functional improvement is significant. It is effective in the treatment of mitral insufficiency and double lesion, and should be performed whenever possible ${ }^{1}$. The most common complication reported is obstruction of the left ventricular outflow tract due to systolic anterior motion of the mitral valve ${ }^{2-7}$. Termini et al ${ }^{2}$ were the first to report this complication in 1977. Its incidence has ranged from 2.7\% to $10 \%{ }^{3,5,7}$. The therapeutic management is controversial between valvar replacement ${ }^{3,6}$ and clinical treatment ${ }^{2,4,5}$. We report a case of severe obstruction of the left ventricular outflow tract after mitral valvuloplasty with implantation of a Gregori's ring, in which the clinical treatment consisted of the suspension of the vasoactive drugs and introduction of a beta-blocker. This is the first report in the literature of implantation of a Gregori's ring.

\section{Case Report}

The patient is a 46-year-old male with dyspnea on strenuous exertion. On physical examination, the patient was short and obese with a body mass index of $34.54 \mathrm{~kg} / \mathrm{m}^{2}$.

Mailing address: Roberto G. de Carvalho - Rua Padre Anchieta, 1923 - $17^{\circ}$ - conj. 1704 - 80730-000 - Curitiba, PR - Brazil - E-mail: rcarvalho50@ hotmail.com English version by Stela Maris C. e Gandour
Cardiac auscultation revealed a systolic regurgitation murmur of $3+/ 4$ with irradiation to the axilla and regular rhythm.

The echocardiographic study showed enlargement of the left atrium and a reduction in the left ventricular function (tab. I). Significant prolapse of the anterior cusp existed due to rupture of the tendinous cords, which allowed a marked reflow. Coronary angiography revealed an obstructive lesion of $60 \%$ in the initial third of the anterior interventricular branch. Considering these data, surgical treatment was indicated and consisted of the revascularization of the anterior interventricular branch through the left internal thoracic artery. In the mitral valve, dilation of the ring, prolapse of the anterior cusp, and rupture of the tendinous cords in their medial part were observed. The aspect of the valve was compatible with myxomatous degeneration with redundant tissue in both cusps. The correction of the valvar prolapse consisted of transposition of the tendinous cords from the posterior cusp to the anterior one. To correct the dilation of the ring, a \#36 Gregori valvuloplasty ring was implanted. The perioperative test showed no reflux through the mitral valve. No difficulty in disconnecting the extracorporeal circulation existed, and the patient was referred to the intensive care unit.

After 18 hours of evolution, the use of vasoactive drugs was required due to the worsening of hemodynamic condition. Even increasing the dosages of the drugs, no hemodynamic improvement occurred, mainly the heart rate, which remained elevated. On cardiac auscultation, a systolic murmur could be heard on the entire precordium. Transesophageal echocardiographic study was performed and showed a significant obstruction of the left ventricular outflow tract, due to systolic anterior motion of the mitral valve. Complete contact of the anterior cusp with the ventricular septum occurred, leading to a systolic pressure gradient between the left ventricle and the aorta of $130 \mathrm{mmHg}$ (fig. 1). Despite the elevated pressure gradient, the management was clinical treatment with suspension of the vasoactive drugs, digitalis, and the diuretic. An intravenous beta- 


\begin{tabular}{|c|c|c|c|c|c|c|}
\hline \multicolumn{7}{|c|}{$\begin{array}{l}\text { Table I - Echocardiographic data in the preoperative period, } 1 \text { and } \\
7 \text { days after surgery, and } 2 \text { years after surgery }\end{array}$} \\
\hline \multicolumn{7}{|c|}{ Echocardiographic data } \\
\hline & $\begin{array}{c}\text { LVDD } \\
(\mathrm{mm})\end{array}$ & $\begin{array}{c}\text { LA } \\
(\mathrm{mm})\end{array}$ & $\begin{array}{l}\text { VS } \\
(\mathrm{mm})\end{array}$ & $\begin{array}{l}\text { Shortening } \\
\quad(\%)\end{array}$ & $\begin{array}{l}\text { Ejection } \\
\text { fraction }\end{array}$ & $\begin{array}{l}\text { Grad. } \\
\mathrm{mmHg}\end{array}$ \\
\hline PRÉ & 51 & 59 & 10 & 39 & 0,70 & 0 \\
\hline $1 \mathrm{dPOST}$ & - & - & - & - & - & 130 \\
\hline $7 \mathrm{dPOST}$ & 59 & 49 & 11 & 23 & 0,45 & 5 \\
\hline $2 \mathrm{yPOST}$ & 53 & 38 & 11 & 38 & 0,76 & 0 \\
\hline \multicolumn{7}{|c|}{$\begin{array}{l}\text { LA- left atrium; LVDD- left ventricular diastolic dimension; Grad. - } \\
\text { pressure gradient between the left ventricle and the aorta (mm Hg); VS- } \\
\text { ventricular septum; PRE- preoperative period; } 1 \mathrm{dPOST} \text { - first } \\
\text { postoperative day; 7dPOST- } 7^{\text {th }} \text { postoperative day; 2yPOST- } 2 \text { nd } \\
\text { postoperative year; mm- millimeters. }\end{array}$} \\
\hline
\end{tabular}

blocker was initiated and the effective circulating volume was increased through infusion of blood and its derivatives. After these measures, a progressive hemodynamic improvement occurred. An echocardiographic study performed after 6 days showed no obstruction of the left ventricular outflow tract (pressure gradient between the left ventricle and the aorta of only $5 \mathrm{mmHg}$ ) and an efficient mitral valvuloplasty. Evolution of the drug dosages and the hemodynamic parameters is shown in figure 2 . Table I shows the patient's echocardiographic data.

The patient was discharged on the $10^{\text {th }}$ postoperative day, and 2 years after the surgery, he is asymptomatic and has a normal life.

\section{Discussion}

After the first report of systolic anterior dislocation of the mitral valve leading to obstruction of the left ventricular outflow tract by Termini et al in $1977^{2}$, a few studies on this topic have been published ${ }^{3-10}$. Some studies report the mechanisms of action of the left ventricular outflow tract

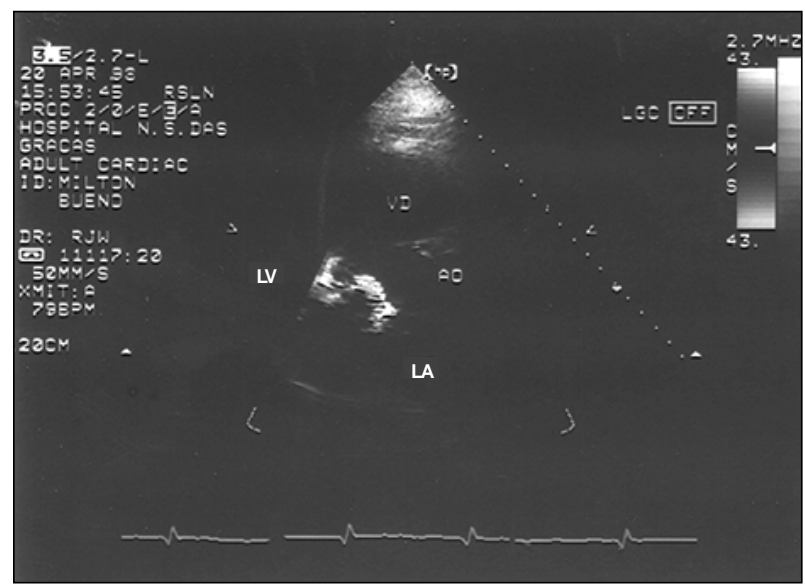

Fig. 1 - Echocardiographic study showing the systolic anterior motion of the anterior cusp of the mitral valve, causing left ventricular outflow tract obstruction. LAleft atrium; LV-left ventricle; LVOFT - left ventricular outflow tract; SAM- systolic anterior motion of the mitral valve. Note: this examination was performed when the pressure gradient between the left ventricle and the aorta was $130 \mathrm{mmHg}$.

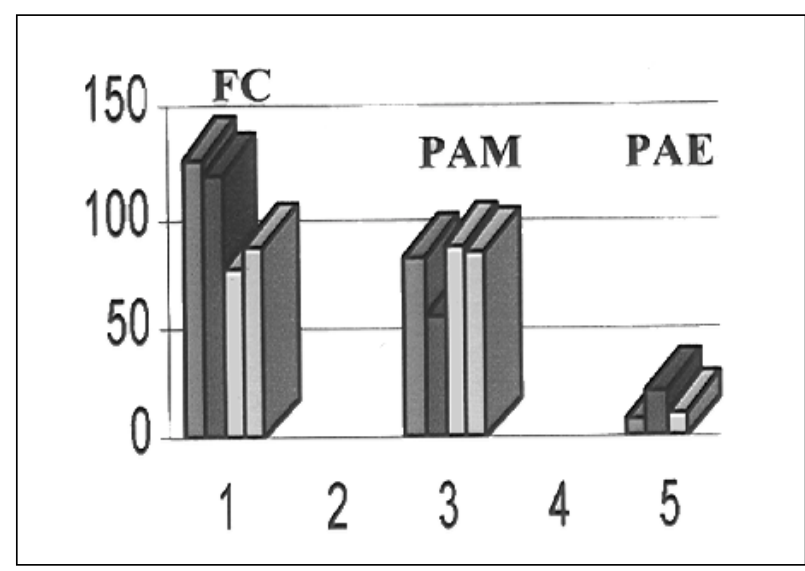

Fig. 2 - Evolution of the hemodynamic parameters of heart rate (bpm), mean blood pressure $(\mathrm{mmHg})$, and left atrial pressure $(\mathrm{mmHg})$.

obstruction and its triggering factors ${ }^{3,5,8}$; others report the surgical technique for its prevention ${ }^{9,10}$ and also its late evolution ${ }^{5-7}$. We report the first national case of left ventricular outflow tract obstruction after implantation of a Gregori ring.

The anatomic aspects, such as the mitral complex, are peculiar in this type of complication. In the present case, redundancy of the valvar tissue existed in both cusps, as the most common etiology is myxomatous degeneration. In the experience of Lee et $\mathrm{al}^{3}$, of 1,045 patients undergoing mitral valvuloplasty, the 22 patients with obstruction of the left ventricular outflow tract had this pathological entity. This fact was also reported by Schiavone et $\mathrm{al}^{6}$ who operated upon 200 patients with myxomatous degeneration and observed obstruction of the left ventricular outflow tract in 12 patients. The authors concluded that rheumatic disease could hardly be the cause of this complication, due to the rigidity of the cusps and of the tendinous cords observed in that disease. The posterior cusp was more frequently involved than the anterior one, according to the observations of Kupferschmid et $\mathrm{al}^{4}$, and its involvement occurred in $50 \%$ (41 out of 82) of the patients in the experience of Jebara et $\mathrm{al}^{10}$. In our patient, redundancy of the anterior cusp and rupture of the tendinous cords occurred.

Alterations in the dimensions of the left ventricular outflow tract after surgical correction are other anatomical findings of left ventricular outflow tract obstruction. When it occurred, a significant reduction in its diameter was observed after valvuloplasty ${ }^{3,6,7}$. In the experience of Lee et $\mathrm{al}^{3}$, a reduction in the diameter of the left ventricular outflow tract from $26.5 \mathrm{~mm}$ in the preoperative period to $17.4 \mathrm{~mm}$ in the postoperative period occurred. Schiavone et $\mathrm{al}^{6}$ observed a $31 \%$ reduction in this diameter (from $32 \mathrm{~mm}$ to $22 \mathrm{~mm}$ ). Galler et $\mathrm{al}^{7}$ reported a decrease in the diameter of the left ventricular outflow tract in the postoperative period (from $28.1 \mathrm{~mm}$ to $22.8 \mathrm{~mm}$ ). Consequently, this narrowing of the outflow tract increases the velocity of blood flow (Bernoulli effect) and, therefore, the anterior cusp slides towards the ventricular septum (Venturi effect). In addition, the reduction in the final left ventricular diastolic diameter 
after valvuloplasty is of significant value as already stressed ${ }^{1}$. The reduction in the left ventricular cavity associated with narrowing of the left ventricular outflow tract and the excessive amount of tissue in the mitral valve cusps favor the appearance of systolic anterior motion of the mitral valve.

Narrowing of the left ventricular outflow tract results in a pressure gradient between the left ventricle and the aorta. In the case we report, the pressure gradient measured at the moment of the greatest hemodynamic decompensation was $130 \mathrm{mmHg}$. Some studies have reported this gradient ${ }^{5-7}$. Grossi et $\mathrm{al}^{5}$, in their experience of 28 cases, reported only 1 patient with a gradient higher than $100 \mathrm{mmHg}$. Schiavone et $\mathrm{al}^{6}$, in 12 cases with systolic anterior motion, found 5 patients with a gradient between 40 and $90 \mathrm{~mm} \mathrm{Hg}$; Galler et al ${ }^{7}$ showed a lower gradient, between 10 and $64 \mathrm{mmHg}$. Therefore, our patient had one of the highest pressure gradients reported in the literature. The pressure value is useful for evolution control. In the experience of Grossi et al ${ }^{5}$, complete regression occurred in $100 \%$ of the patients within 32 months, similar to our patient's evolution, who had no pressure gradient after 24 months.

In regard to the type of ring used for valvuloplasty, it is believed that one of the factors triggering the systolic anterior motion is the presence of the rigid ring ${ }^{5,7}$. This ring would displace the posterior wall towards the ventricular septum, reducing the mitral-aortic angle. But left ventricular outflow obstruction was observed in patients in whom no ring had been used, as in the first case reported in the literature $^{2}$, and also in the study by Kupferschmid et $\mathrm{al}^{4}$. The Cleveland Clinic group ${ }^{3}$ reported 22 patients with left ventricular outflow tract obstruction, and, in 14 of them, a bovine pericardial band was used for posterior annuloplasty. The Gregori ring is considered semirigid because only the posterior part is rigid ${ }^{1}$, but this fact does not impede the appearance of left ventricular outflow tract obstruction. After mitral valvuloplasty, where an excessive amount of the cusp tissue exists, the coaptation point occurs more anteriorly, ie, closer to the left ventricular outflow tract. In that manner, independent from the presence or absence of the rigid or flexible ring, left ventricular outflow tract obstruction may occur. In an experimental study by Dagum et $\mathrm{al}^{8}, 2$ types of ring were assessed, a flexible (Duran) and a semiflexible (PhysioRing), to explain the mechanism of left ventricular outflow tract obstruction after mitral annuloplasty. Using the semiflexible ring, the entire structure of the mitral valve (cusps, tendinous cords, and papillary muscle) was observed moving towards the ventricular septum in the maximum ventricular ejection period. Therefore, the semiflexible ring underwent dynamic perturbation of the mitral ring, causing alterations in the geometry of the papillary muscles, which did not happen to the flexible ring.

Basically, 2 surgical techniques exist to prevent the appearance of systolic anterior motion ${ }^{9,10}$. The most used was reported by Jebara et al ${ }^{10}$. Because of the excessive amount of tissue in the cusps, mainly in the posterior one, this technique "sliding leaflet" aims to reduce the height of the posterior cusp, and prevents the coaptation point of the cusps from being located more anteriorly, ie, in the left ventricular outflow tract. Prior to this technique, the index of systolic anterior motion was $14 \%$ and zero after the procedure. This technique should be used in patients at risk, ie, those with normal or small ventricular cavity, excessive amount of tissue in the mitral valve cusps, implantation or no implantation of the valvuloplasty ring, wide quadrilateral resection of the posterior cusp, and myxomatous or fibroelastic degeneration of the mitral valve. Another technique reported by Grossi et al ${ }^{9}$ consists in the triangular resection of the anterior cusp. Prior to its use, the incidence of systolic anterior motion was $9.1 \%$ and, with its use, the incidence is $3.4 \%$. When the anterior cusp is excessive (Barlow syndrome), and after implantation of the valvuloplasty ring, the coaptation point of the anterior cusp with the posterior one will be much closer to the septum, leading to obstruction of the left ventricular outflow tract. The triangular resection aims at enlarging the distance between the coaptation point of the cusps and the ventricular septum.

Management of left ventricular outflow tract obstruction is still controversial, arguments being between mitral valve replacement or valvuloplasty redo ${ }^{3,6}$ and clinical treatment ${ }^{2,4,5}$. Lee et $\mathrm{al}^{3}$ chose mitral valve replacement after the appearance of left ventricular outflow tract obstruction. In their experience, mortality in reoperation was $27 \%$. Extracorporeal circulation and aortic clamping may lead to general disorders, such as the inflammatory response following extracorporeal circulation with release of vasoactive substances and activation of the complement, and myocardial ischemia with cellular edema. In conditions in which reoperation is elective, mortality and morbidity are high. Considering all these aspects, the conservative management is the best option, with suspension of the vasoactive drugs and introduction of a beta-blocker. The hyperkinetic status tends to increase the pressure gradient due to the Bernoulli and Venturi effect. The beta-blocker leads to a reduction in heart rate and lower oxygen consumption. Management is similar to that adopted for patients with asymmetric septal hypertrophy ${ }^{5}$. As observed in the present case, during the use of high doses of vasoactive drugs, the pressure gradient was $130 \mathrm{mmHg}$. After their suspension and introduction of the beta-blocker, the gradient decreased to $5 \mathrm{mmHg}$ in 48 hours. Another aspect that should be commented on is the increase in the effective circulating volume. The hypovolemic and hyperkinetic status may lead to the appearance of systolic anterior motion ${ }^{2}$, and, associated with a reduction in the left ventricular cavity, this scenario tends to worsen. If the patient has only obstruction with no mitral insufficiency, the clinical treatment is a good option, even in the presence of a high pressure gradient, as in the case reported.

The late outcome of these patients is favorable. In the case series of Grossi et $\mathrm{al}^{5}$, after a mean period of 44 months, the pressure gradient between the left ventricle and the aorta was null in all patients, and no valvar replacement due 
to this complication was required. Schiavone et al ${ }^{6}$ observed that even when the obstruction phenomenon persisted later, the patients improved clinically, and none of them required valvar replacement. Galler et al ${ }^{7}$ carried out an echocardiographic study in some patients and observed a significant reduction in the left ventricular diameter and an increase in the left ventricular outflow tract diameter. But when they performed the test with amyl nitrite, the gradient appeared in all patients, showing that this is a dynamic situation. The late outcome of these patients depends on the results of the valvuloplasty itself. In our patient, 2 years after surgery, no pressure gradient existed and the left ventricular function had improved.

In conclusion, the major factors that may lead to systolic anterior motion of the mitral valve causing left ventricular outflow tract obstruction are as follows: normal or small ventricular cavity, an excessive amount of tissue in both cusps, wide quadrilateral resection of the posterior cusp, and annuloplasty. When this complication occurs, clinical treatment with suspension of the vasoactive drugs and introduction of a beta-blocker is the best management.

\section{References}

1. Carvalho RG, Giublin PR, Lopes LR, Mulinari LA, Loures DR. Plástica da valva mitral com emprego do anel de Gregori-Braile: análise de 66 pacientes. Rev Bras Cir Cardiovasc 1998; 13: 295-316.

2. Termini BA, Jackson PA, William CD. Systolic anterior motion of the mitral valve following annuloplasty. Vasc Surg 1977; 11: 55-60.

3. Lee KS, Stewart WJ, Lever HM, Underwode PL, Cosgrove DM. Mechanism of outflow tract obstruction causing failed mitral valve repair: anterior displacement of leaflet coaptation. Circulation 1993; 88(part 2): 24-9.

4. Kupferschmid JP, Carr T, Connelly GP, Shemin RJ. Systolic anterior motion of the mitral valve after repair without an annular ring. Ann Thorac Surg 1994; 57: 484-6.

5. Grossi EA, Galloway AC, Parish MA, et al. Experience with twenty-eight cases of systolic anterior motion after mitral valve reconstruction by Carpentier technique. J Thorac Cardiovasc Surg 1992; 103: 466-70.

6. Schiavone WA, Cosgrove DM, Lever HM, Stewart WJ, Salcedo EE. Long-term follow-up of patients with left ventricular outflow obstruction after Carpentier ring mitral valvuloplasty. Circulation 1988; 78(suppl I): I-60-I-65.

7. Galler M, Kronzon I, Slater JL, et al. Long-term follow-up after mitral valve reconstruction: incidence of postoperative left ventricular outflow obstruction. Circulation 1986; 74(suppl I): I-99-I-103.

8. Dagum PD, Green RG, Glasson JR, et al. Potential mechanism of left ventricular outflow tract obstruction after mitral ring annuloplasty. J Thorac Cardiovase Surg 1999; 117: 472-80.

9. Grossi EA, Steinberg BM, LeBouitiller MIII, Ribacove FC, Galloway AC, Colvin SB. Decreasing incidence of systolic anterior motion after mitral valve reconstruction. Circulation 1994; 90(part2): II-195-II-197.

10. Jebara VA, Mihaileanu S, Acar C, et al. Left ventricular outflow tract obstruction after mitral valve repair: results of the sliding leaflet technique. Circulation 1993; 88(part 2): 30-4. 